\title{
1
}

\section{Polymer Reaction Engineering, an Integrated Approach}

\author{
Th. Meyer and J. T. F. Keurentjes
}

1.1

Polymer Materials

Synthetic polymers can be denoted as the materials of the 20th century. Since World War II the production volume of polymers has increased by a factor of 50 to a current value of more than 120 million tonnes annually (Figure 1.1). The consumption per capita has also increased over the years to a worldwide average of approximately $20 \mathrm{~kg}$ per annum in the year 2000. In terms of volumetric output, the production of polymers exceeds that of iron and steel. The enormous growth of synthetic polymers is due tot the fact that they are lightweight materials, act as insulators for electricity and heat, cover a wide range of properties from soft packaging materials to fibers stronger than steel, and allow for relatively easy processing.

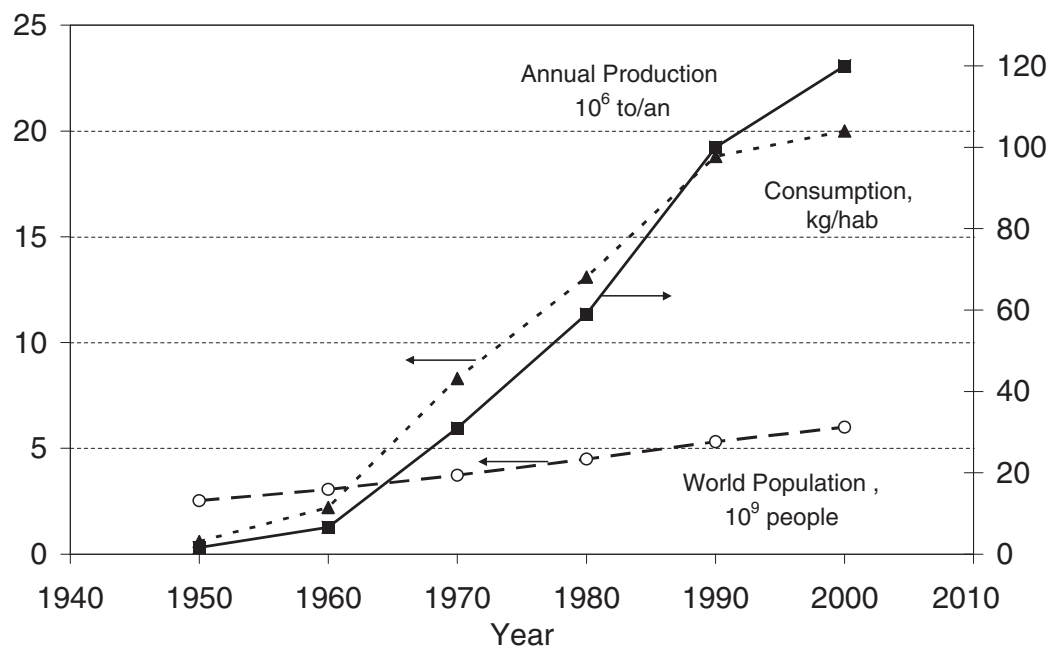

Fig. 1.1. Polymer production and the evolution of the population since 1940 [1].

Handbook of Polymer Reaction Engineering. Edited by T. Meyer, J. Keurentjes

Copyright @ 2005 WILEY-VCH Verlag GmbH \& Co. KGaA, Weinheim

ISBN: 3-527-31014-2 
$2 \mid 1$ Polymer Reaction Engineering, an Integrated Approach

Tab. 1.1. Applications and 2002 Western European markets for the major thermoplastics [1].

\begin{tabular}{|c|c|c|}
\hline Thermoplastic & $\begin{array}{l}\text { Market } \\
{\left[10^{3} \text { tonnes }\right]}\end{array}$ & Applications \\
\hline LDPE & 7935 & $\begin{array}{l}\text { pallet and agricultural film, bags, toys, coatings, } \\
\text { containers, pipes }\end{array}$ \\
\hline $\mathrm{PP}$ & 7803 & $\begin{array}{l}\text { film, battery cases, microwave-proof containers, crates, } \\
\text { automotive parts, electrical components }\end{array}$ \\
\hline PVC & 5792 & $\begin{array}{l}\text { window frames, pipes, flooring, wallpaper, bottles, cling } \\
\text { film, toys, guttering, cable insulation, credit cards, } \\
\text { medical products }\end{array}$ \\
\hline HDPE & 5269 & $\begin{array}{l}\text { containers, toys, housewares, industrial wrappings and } \\
\text { films, pipes }\end{array}$ \\
\hline PET & 3234 & bottles, textile fibers, film food packaging \\
\hline PS/EPS & 3279 & $\begin{array}{l}\text { electrical appliances, thermal insulation, tape cassettes, } \\
\text { cups and plates, toys }\end{array}$ \\
\hline PA & 1399 & $\begin{array}{l}\text { film for food packaging (oil, cheese, "boil-in-bag"), high- } \\
\text { temperature engineering applications, textile fibers }\end{array}$ \\
\hline ABS/SAN & 788 & general appliance moldings \\
\hline PMMA & 317 & $\begin{array}{l}\text { transparent all-weather sheet, electrical insulators, } \\
\text { bathroom units, automotive parts }\end{array}$ \\
\hline
\end{tabular}

Moreover, parts with complex shapes can be made at low cost and at high speed by shaping polymers or monomers in the liquid state.

The polymer market can be divided into thermoplastics and thermosets. The major thermoplastics include high-density polyethylene (HDPE), low-density polyethylene (LDPE), polyethylene terephthalate (PET), polypropylene (PP), polystyrene (PS and EPS), poly(vinyl chloride) (PVC), polyamide (PA), poly(methyl methacrylate) (PMMA) and styrene copolymers (ABS, SAN). The most important applications of thermoplastics are summarized in Table 1.1. The total Western European demand for thermoplastics was 37.4 million tonnes in 2002, a growth of about $9 \%$ as compared to 2001 [1]. Thermoplastics are used not only in the manufacture of many typical plastics applications such as packaging and automotive parts, but also in non-plastic applications such as textile fibers and coatings. These non-plastic applications account for about $14 \%$ of all thermoplastics consumed.

The major thermosets include epoxy resins, phenolics, and polyurethanes (PU), for which the major applications are summarized in Table 1.2. It has to be noted,

Tab. 1.2. Applications and 2002 Western European markets for the major thermosets [1].

\begin{tabular}{lcl}
\hline Thermoset & Market $\left[\mathbf{1 0}^{\mathbf{3}}\right.$ tonnes] & Applications \\
\hline PU & 3089 & $\begin{array}{l}\text { coatings, finishes, cushions, mattresses, vehicle seats } \\
\text { general appliance moldings, adhesives, appliances, } \\
\text { automotive parts, electrical components } \\
\text { adhesives, automotive components, E\&E components, } \\
\text { sports equipment, boats }\end{array}$ \\
Epoxy resins & 412 &
\end{tabular}




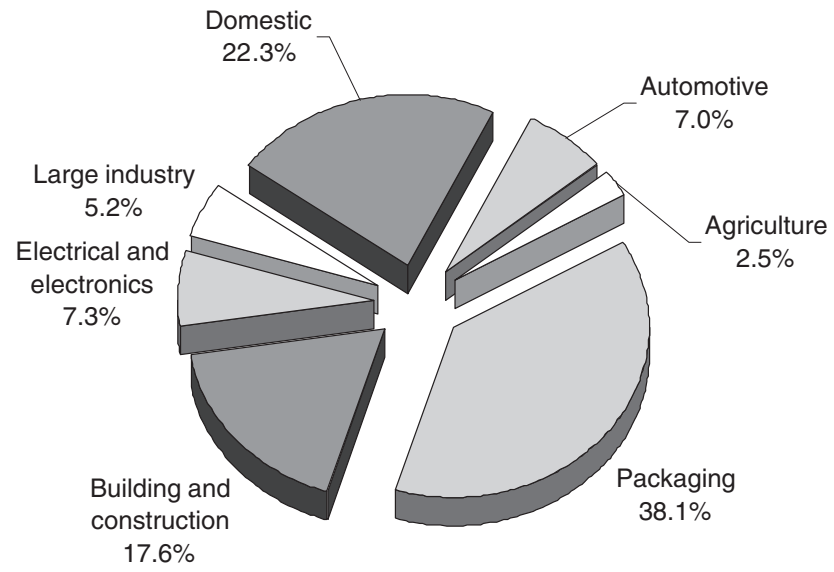

Fig. 1.2. Plastic consumption in 2002 by industry sectors in Western Europe [1].

however, that about one-third of the market for thermosets is for relatively smallscale specialty products. The total Western European market for thermosets was 10.4 million tonnes in 2002, about $1 \%$ below the 2001 value.

The major application areas of polymers can be defined as follows (Figure 1.2).

Automotive industry Motorists want high-performing cars combined with reliability, safety, comfort, competitive pricing, fuel efficiency, and, increasingly, reassurance about the impact on the environment. Lightweight polymeric materials are increasingly used in this sector (Daimler Benz's Smart is a nice example), also contributing to a $10 \%$ reduction in passenger fuel consumption across Europe.

Building and construction Polymeric materials are used in the building and construction sector, for example for insulation, piping, and window frames. In 2002 this sector accounted for $17.6 \%$ of the total polymer consumption.

Electrical and electronic industry Many applications in this field arise from newly designed polymeric materials, for example for polymeric solar cells and holographic films. It is interesting to note that, while the number of applications in this field is increasing, the weight of the polymers used per unit is decreasing.

Packaging The packaging sector remains the largest consumer of synthetic polymers, approximately $38 \%$ of the total market. This is mainly due to the fact that these materials are lightweight, flexible, and easy to process, and are therefore increasingly being substituted for other materials. Although polymer packaging ranks first in terms of units sold, it is only third if judged on weight.

Agriculture As agricultural applications account for about $2.5 \%$ of the total of synthetic polymers consumed in Europe, they play only a marginal role. Irrigation and 


\section{$4 \mid 1$ Polymer Reaction Engineering, an Integrated Approach}

drainage systems provide effective solutions to crop growing, and polymeric films and greenhouses can increase horticultural production substantially. The use of socalled "super absorbers" for increased irrigation efficiency in arid areas can be considered an important emerging market.

1.2

\section{A Short History of Polymer Reaction Engineering}

In Table 1.3 a comprehensive overview of the major developments in the polymer industry is given. In the 19th century, polymers produced by Nature, such as cellulose, Hevea brasiliensis latex (natural rubber), and starch, were processed to manufacture useful products. This practice was often based on experimental discoveries. As an example, in 1839 Goodyear discovered by mistake the sulfur vulcanization of natural rubber, making it possible for Ford to develop the automotive market. In those times no polymers were produced synthetically.

Early in the 20th century (1920), the first empirical description of macromolecules was developed by Staudinger [2]. At the same time, new methods were developed to determine the specific characteristics of these materials. In the 1930s many research groups (for examples see refs. 3-7) developed models for the chain length distribution in batch reactors resulting from different polymer chemistries, a methodology that was further developed in the 1940s leading to more complex and comprehensive models, some of which are still being used today.

Tab. 1.3. The history of polymers in brief.

\begin{tabular}{|c|c|}
\hline 19th century & natural polymer and derivatives (vulcanized rubber, celluloid) \\
\hline 1920 & concept of macromolecules postulated by Staudinger \\
\hline \multirow[t]{2}{*}{ 1930-1940 } & first systematic synthesis of polymers \\
\hline & $\begin{array}{l}\text { synthesis of polyamides (nylon) by Carothers at DuPont } \\
\text { discovery of polyethylene at ICI (Fawcett and Gibson) }\end{array}$ \\
\hline 1940-1950 & synthetic rubbers and synthetic fibers \\
\hline \multirow[t]{2}{*}{ 1950-1960 } & $\begin{array}{l}\text { stereospecific polymerizations by Ziegler and Natta, the birth of } \\
\text { polypropylene }\end{array}$ \\
\hline & $\begin{array}{l}\text { discovery of polymer single crystals (Keller, Fischer, Till) } \\
\text { development of polycarbonate }\end{array}$ \\
\hline 1960-1970 & $\begin{array}{l}\text { discovery of PPO at GE by Hay and commercialization of PPO/PS } \\
\text { blends }\left(\text { Noryl }^{\mathbb{R}}\right)\end{array}$ \\
\hline 1970-1980 & liquid-crystalline polymers \\
\hline \multirow[t]{2}{*}{ 1980-1990 } & superstrong fibers (Aramid ${ }^{\circledR}$, polyethylene) \\
\hline & functional polymers (conductive, light-emitting) \\
\hline 1990-2000 & $\begin{array}{l}\text { metallocene-based catalysts; novel polyolefins hybrid systems } \\
\quad(\text { polymer/ceramic, polymer/metals) }\end{array}$ \\
\hline $2000-$ & $\begin{array}{l}\text { Nature-inspired catalysts } \\
\text { synthesis of polymers by bacteria and plants }\end{array}$ \\
\hline
\end{tabular}


Around 1940, partly inspired by World War II, a more systematic search for new synthetic polymer materials as a replacement for scarce natural materials led to the development of nylon (DuPont) and polyethylene (ICI) $[8,9]$. This was followed by the development of synthetic rubbers and synthetic fibers. In the same period, Denbigh [10] was one of the first to introduce chemical reaction engineering concepts into polymer science by considering polymerization reactions at both the chemical and at the process levels. Processes were classified as homocontinuous and heterocontinuous, depending on the mixing level. This pioneering approach also acted as a catalyst for the further development of polymer reaction engineering (PRE).

The development of catalysts based on transition metals by Ziegler and Natta [11] allowed the development of stereospecific propylene polymerization processes and ethylene polymerization in the 1950s. Several process schemes were developed at that time, of which some are still in use. The major problem in process development has been to deal with the heat of polymerization, an issue that was solved, for example, by using an inert solvent as a heat sink or by flashing of monomer followed by condensation outside the reactor. In the same period, polycarbonate and (somewhat later) poly(propylene oxide) (PPO) were developed. The main characteristic of the polymers developed so far was that they were bulk materials, to be produced in extremely large quantities.

In the 1970s, a paradigm shift occurred when polymers with more specific properties started to be produced. This included various liquid crystalline polymers leading, for example, to the production of superstrong fibers such as Aramid $^{\circledR} /$ $\operatorname{Kevlar}^{\circledR}[12]$. The development of functional polymers for the conduction of light and electricity and optical switches also started then [13]. In the near future this will probably lead to highly effective and flexible polymer solar cells [14].

In the 1990s, metallocene catalysts were developed for polyolefin production that surpassed the Ziegler-Natta catalysts in terms of selectivity and reactivity $[15,16]$. Additionally, various hybrid materials were combining properties of both the polymer (lightweight, flexible) and a solid material, which could be metal (conductive) or ceramic (insulating), leading to materials with specific properties applicable, for example, as protective coatings [17].

Current developments include the mimicking of nature (enzymes) for the synthesis of quite complex polymers like natural silk. Also, bacteria and plants are being modified to produce polymers of interest [18]. However, this can be expected to require polymer reaction engineering developments that are as yet difficult to foresee.

\section{3}

\section{The Position of Polymer Reaction Engineering}

Traditional chemical reaction engineering has its basis in the application of scientific principles (from disciplines such as chemistry, physics, biology, and mathematics) and engineering knowledge (transfer of heat, mass, and momentum) to 


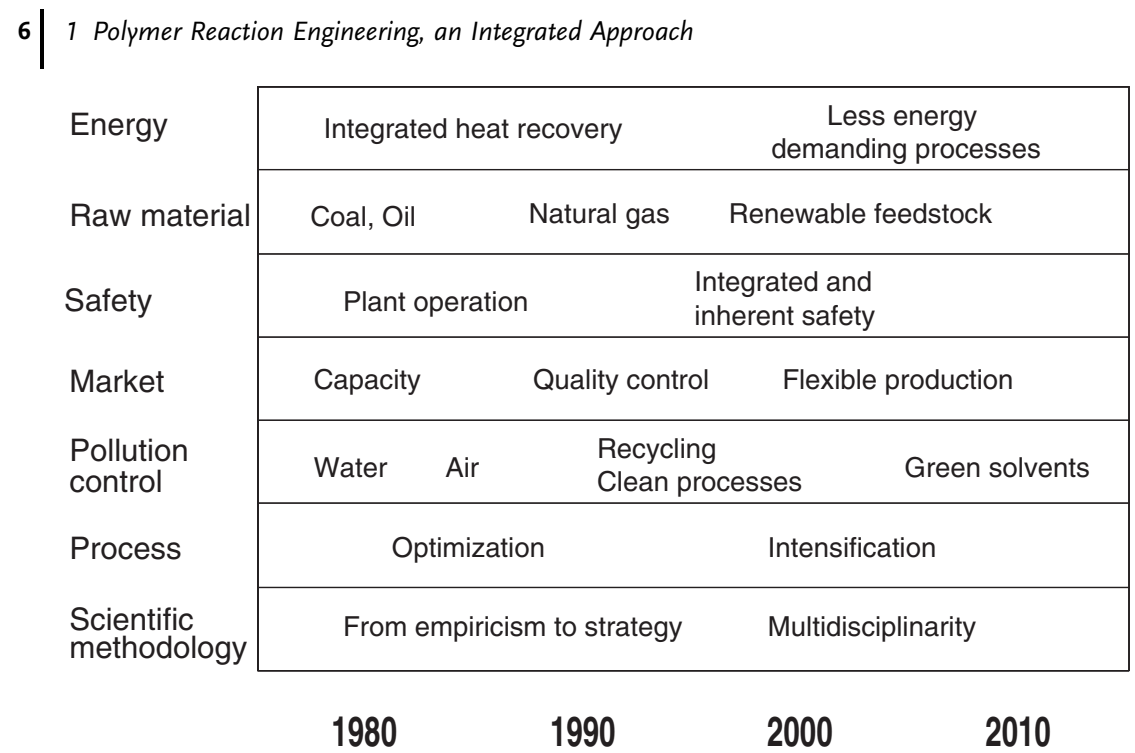

Fig. 1.3. Changing priorities in industrial chemical engineering research.

the solution of problems of practical, industrial, and societal importance. Since the 1970 s, a changing focus in chemical reaction engineering can be observed, which is summarized in Figure 1.3.

To deal with more stringent requirements in terms of energy consumption requires a shift from heat loss minimization toward novel intensified process concepts that intrinsically require less energy. Safety should now be considered as an intrinsic plant property rather than a responsive action, and the plant needs to be flexible to be able to respond quickly to changes in the market. Last but not least, new concepts will be required to provide a basis for sustainable future developments, that is, the use of renewable resources and processes based on "green" solvents. As a result of this changing focus, a shift toward a multidisciplinary approach can be observed.

For PRE this implies the combination of several disciplines such as polymer chemistry, thermodynamics, characterization, modeling, safety, mechanics, physics, and process technology. PRE problems are often of a multi-scale and multifunctional nature to achieve a multi-objective goal. One particular feature of PRE is that the scope ranges from the micro scale on a molecular level up to the macro scale of complete industrial systems. PRE plays a crucial role in the transfer of information across the boundaries of different scale regions and to provide a comprehensive and coherent basis for the description of these processes [19].

As depicted in Figure 1.4, there is a direct link between time and size scale, from which it is obvious that the micro and macro scales are not related to the same time scale [20]. As an example, molecular dynamics calculations are addressing a time scale in the order of femto- to nanoseconds, whereas process system integration evolves on the scale of years. Engineers have traditionally been working at the meso scale, which is represented by the middle portion of Figure 1.4, using phe- 


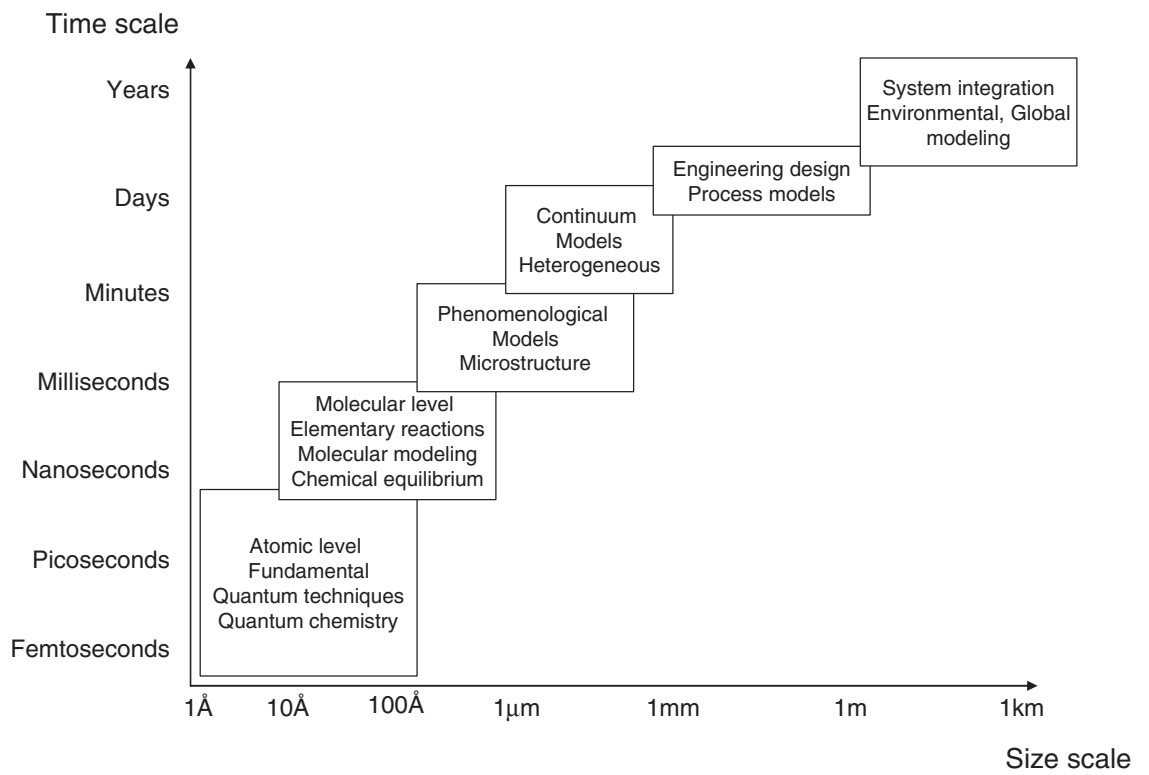

Fig. 1.4. Activities in PRE with their corresponding time and size scales.

nomenological and continuum models. Today these limits are pushed in two directions, both toward a more fundamental understanding and at the same time toward a more global scale. In the past, the "micro-region" has traditionally been the domain of physicists and chemists, whereas the "macro-region" has been the field, rather, of process or plant engineers. Today, it becomes obvious that only using a multidisciplinary, parallel, and synergetic approach can lead to successful developments. Polymer reaction engineering will play an essential role as the core and the coordinator of this complex process.

\section{4}

Toward Integrated Polymer Reaction Engineering

As will be obvious from the foregoing discussion, PRE is composed of many disciplines all linked together. These disciplines can be either mature or emergent, but they have a common gateway (see Figure 1.5). Although there is not necessarily a direct connection between them, there exists a common core in which the different disciplines make their own specific contribution to a general objective.

The frontiers in PRE are determined by what we know, understand, and are able to quantify, and these frontiers are moving with growing knowledge, competences, and experience. Efforts to push these limits will induce innovative developments leading to emerging technologies and products, and will also strengthen the multidisciplinary approach. In general terms, PRE can be defined as the science that 


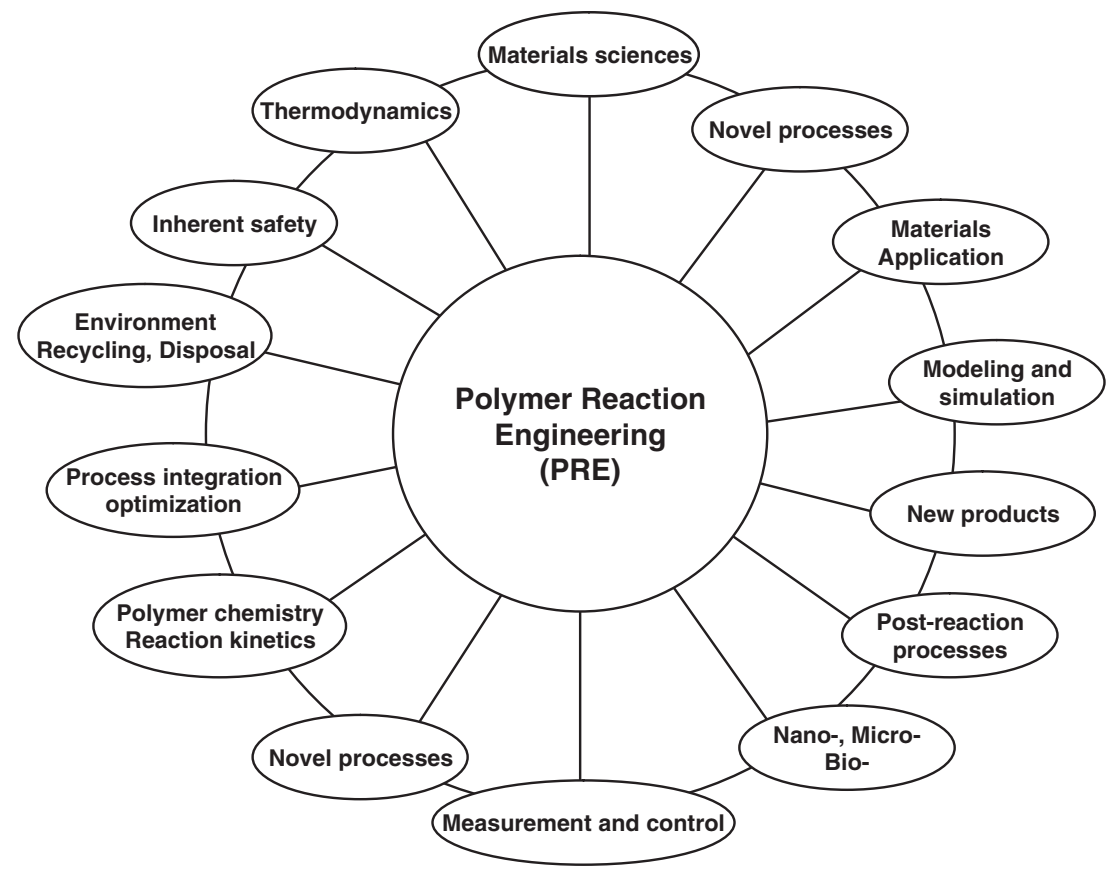

Fig. 1.5. The expanding sphere of polymer reaction engineering.

brings molecules to an end-use product. We can either consider it like a black box (Figure 1.6) or we can try to define the interconnected disciplines that compose this black box (Figure 1.7). Provided the required product properties can be met, we expect that sustainability is the common denominator for all the disciplines involved in this process.

The process of transforming raw materials into valuable end-use products is not a one-way procedure but rather an iterative process in which we try to optimize all the parameters involved. The selection of the proper chemistry and technology should include an evaluation of environmental, safety, and economic parameters. Moreover, questions regarding the possible use of renewable resources and minimizing the energy requirement will have to be answered. Defining PRE in this manner appears to be very close to the procedure of life cycle analysis (LCA) [21].

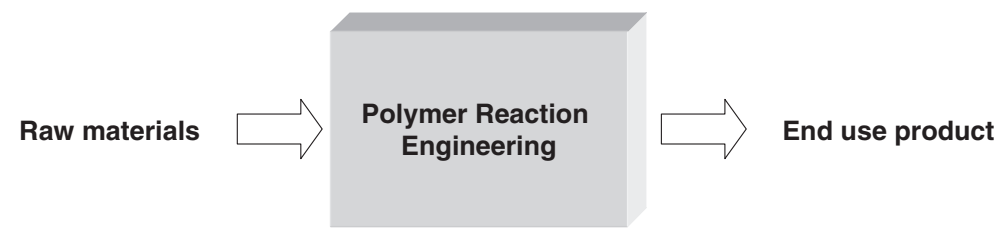

Fig. 1.6. PRE as a black box process. 


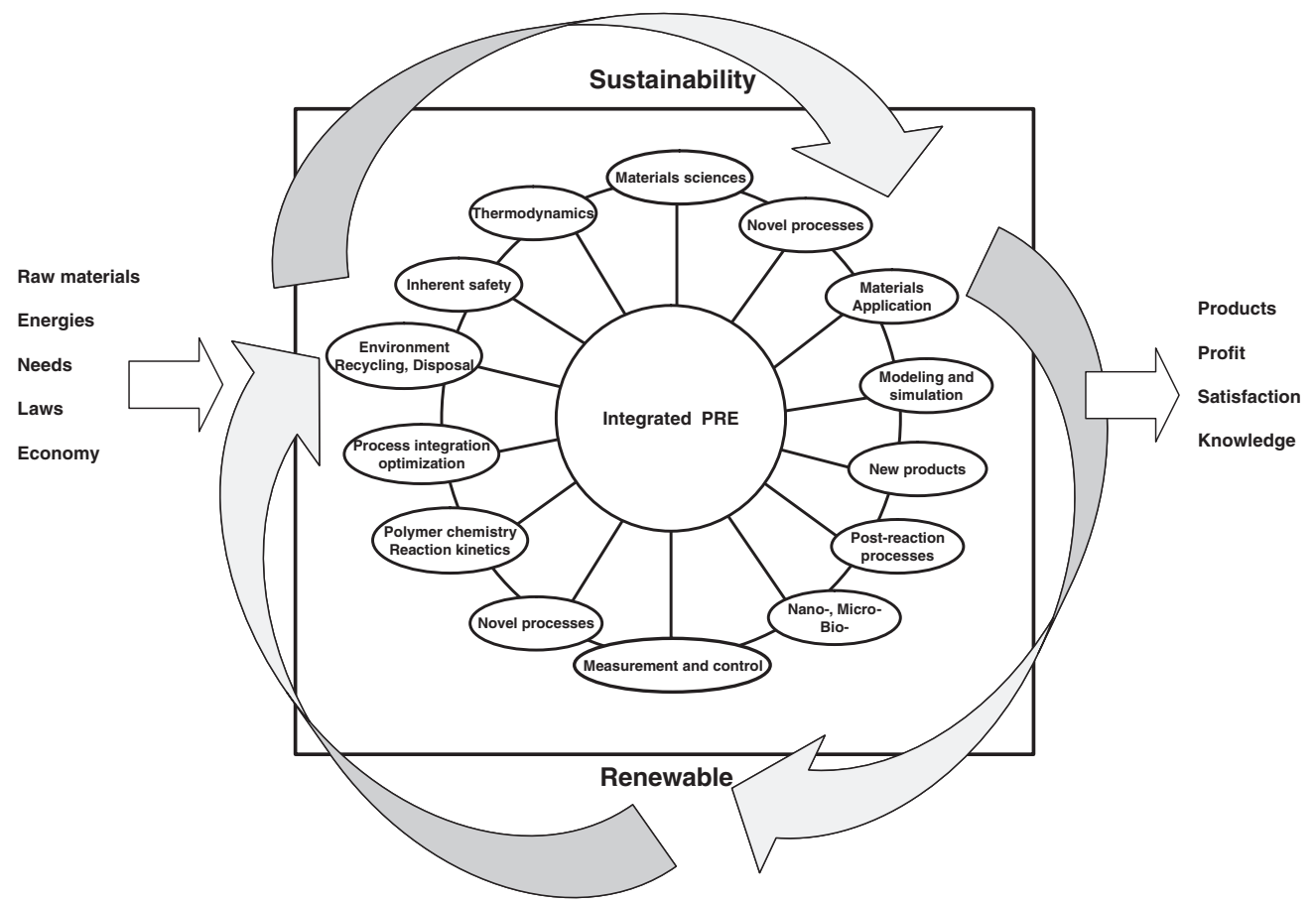

Fig. 1.7. The integrated approach for sustainable PRE.

Life cycle analysis is a tool assisting decision making in the engineering process. LCA includes the information on the history of the materials used, and the different process and raw material alternatives, as well as the final product requirements. LCA is an instrument driven by environmental considerations against a background of technical and economic specifications, and involves the so-called 3P concept (people, planet, and profit). The LCA-based PRE methodology (Figure 1.8) [22] leads to an optimization of all the parameters involved and a reduction of the costs. This seems to be contradictory at first sight, but integrating all the aspects often leads to cost reductions. In our view, the use of this approach will lead to a "sustainable integrated PRE".

\section{5}

\section{The Disciplines in Polymer Reaction Engineering}

The different disciplines involved in PRE can be represented using the academiaindustry dichotomy (Figure 1.9). The interests of the two types of players are not identical: the differences are similar to the differences in their mission statements. Nevertheless, we can observe that a great overlap is present in the middle zone, 


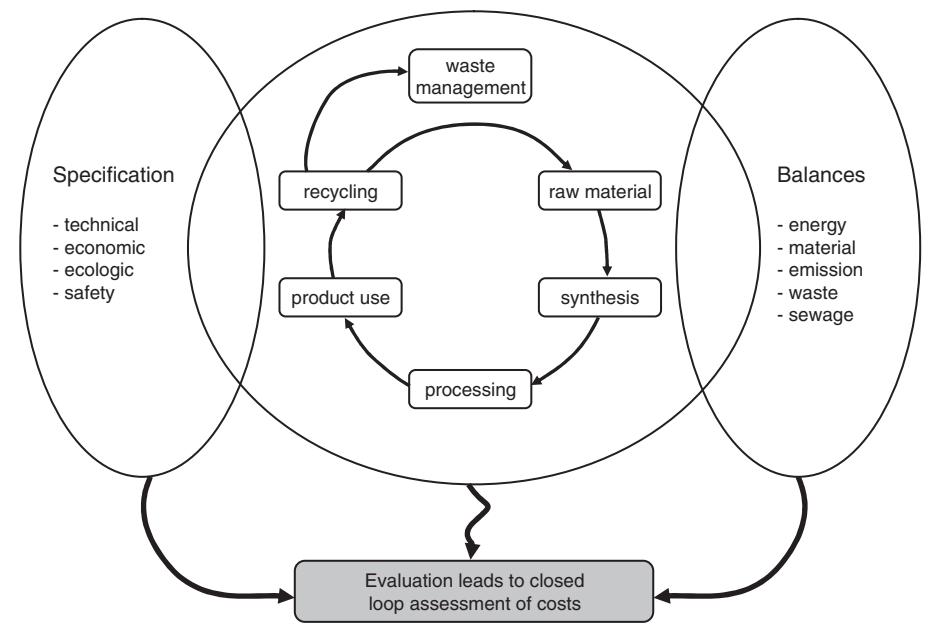

Fig. 1.8. Life cycle analysis of parts, methods, products, and systems.

where interests, tools, and knowledge are similar, thus providing a strong basis for partnership.

As stated above, PRE is composed of a large number of disciplines, which are described in more detail in the following chapters of this handbook. These disciplines are interconnected by a synergetic and multidisciplinary approach, and com-

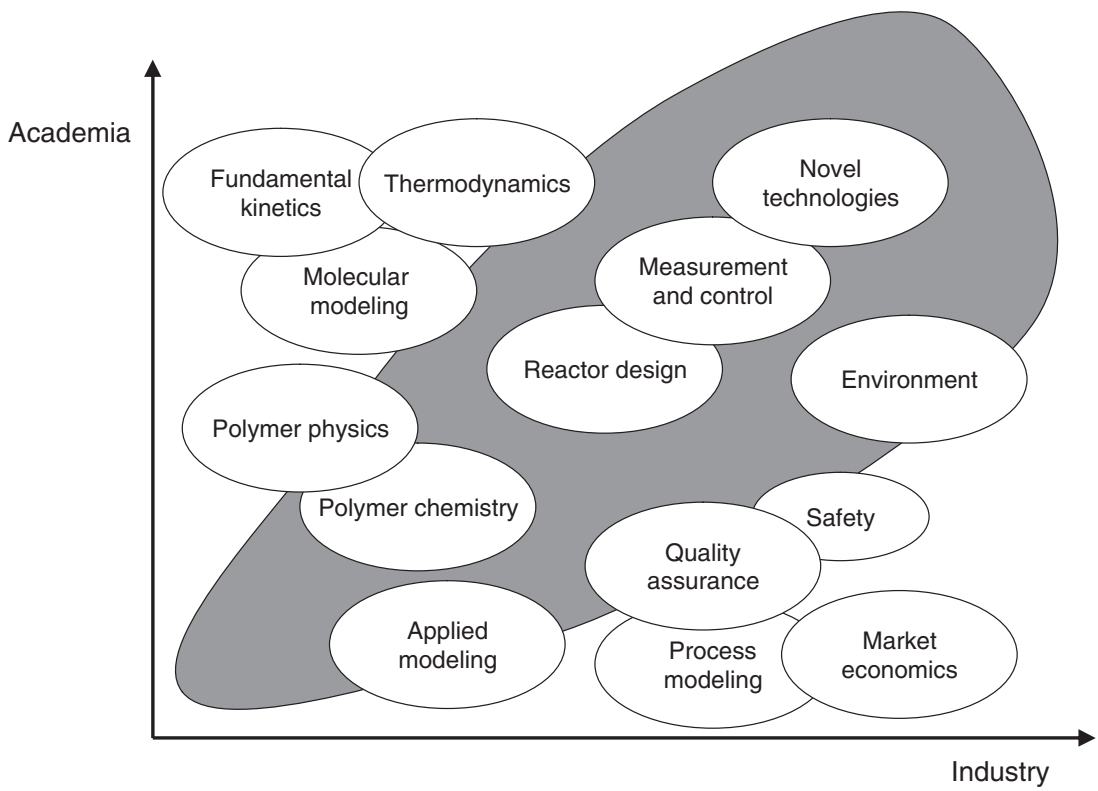

Fig. 1.9. Overlap of industrial and academic disciplines. 


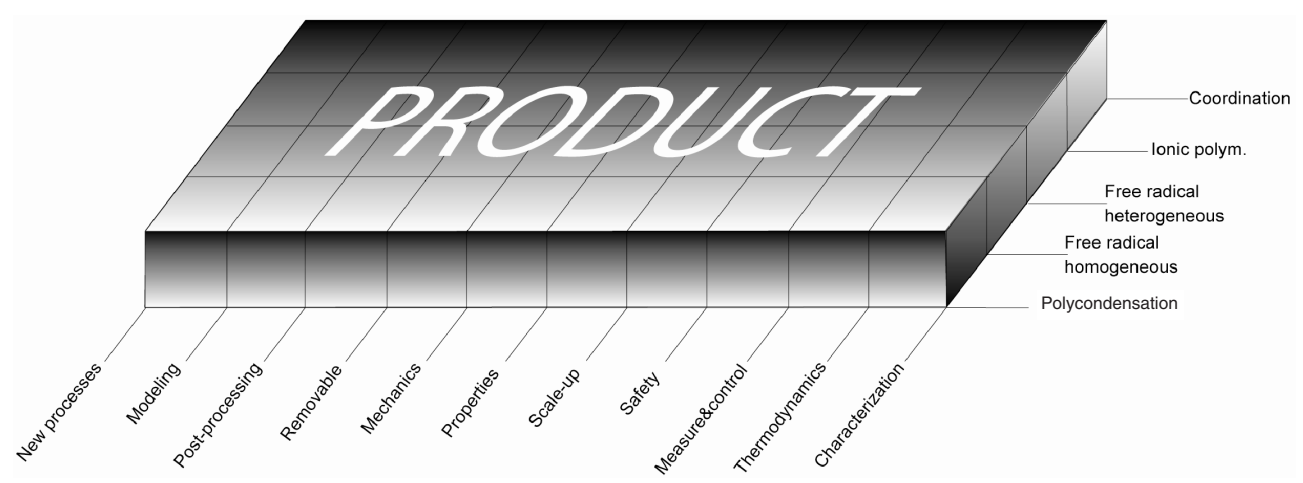

Fig. 1.10. Product-driven PRE, based on an orthogonal

relationship between science and engineering.

mercial products are the final achievement resulting from this methodology. This could be expressed by an orthogonal representation (Figure 1.10) where polymer sciences are linked with engineering sciences. Every type of polymerization will have its own specific features, models, and engineering aspects involved. From Figure 1.10 it will be obvious that only teamwork, bringing together several fields of expertise, can lead to the final objective.

1.5.1

\section{Polymerization Mechanisms}

Polymerization reactions can be classified depending on the reaction mechanism involved and can be either step-growth or chain-growth. These mechanisms differ basically with the time scale of the process. In step-growth polymerization (like polycondensation), the polymer chain growth proceeds slowly from monomer to dimer, trimer, and so on, until the final polymer size is formed at high monomer conversions. Both the chain lifetime and the polymerization time are often in the order of hours. In chain-growth polymerization (like ionic or free-radical polymerization), macromolecules grow to full size in a much shorter time (seconds being the order of magnitude) than required for high monomer conversion. High molecular weights are already obtained at low monomer conversion, which is in great contrast to step-growth polymerizations. Also, unlike step-growth polymerization, chain-growth polymerization requires the presence of an active center.

Condensation polymers are the result of a condensation reaction between monomers, with or without the formation of a condensation by-product (Chapter 3). Examples of polymers produced by condensation are polyamide[6.6], (Nylon 6,6) the result of the intermolecular condensation of hexamethylenediamine and adipic acid, and polyamide[6], (Nylon 6) which is the product of intramolecular condensation of $\alpha$-caprolactam. This type of reaction is generally sensitive to thermodynamic equilibrium and requires the removal of the by-product, which is often volatile. 
$12 \mid 1$ Polymer Reaction Engineering, an Integrated Approach

The polymers produced by condensation reactions can be either linear or nonlinear, depending on the number of functional groups per monomer. The polymerization process can be performed in bulk (liquid or solid state) or as an interfacial polymerization.

Free-radical polymerization (FRP) can be performed homogeneously (in bulk, solution, or suspension; Chapters 4 and 5) or heterogeneously (emulsion, precipitation; Chapter 6). The active site is always a radical that can be unstable (classical FRP) or stabilized as in pseudo-living FRP. Radicals can be formed by the homolytic bond rupture of initiators (molecules sensitive to homolytic cleavage, such as peroxides, photosensitive molecules, or bisazo compounds) or by complex mechanisms creating radicals from monomer units using thermal or high-energy sources, such as X-rays, $\gamma$-irradiation, or UV. This type of polymerization usually comprises several steps: initiation, propagation, various transfer mechanisms, and termination.

In ionic polymerizations a cation or anion is the active site (Chapter 7). A heterolytic process leads to charged parts of molecules that can induce the polymerization by nucleophilic or electrophilic processes. These reactions generally evolve at low temperatures (even as low as $-120^{\circ} \mathrm{C}$ ) due to the high reactivity of ions. Also, they are very sensitive to impurities present in the monomer or solvent. These reactions are not always terminated, so lead to living polymerization. This process is often used to build tailor-made copolymers.

Coordination polymerizations require a transition metal catalyst (Chapter 8). Polyolefins are often produced by this kind of reaction where the catalyst (ZieglerNatta, for example) acts as the active site but also as the steric regulator, which makes it possible to build polymers with a defined tacticity. Nowadays a great research effort is devoted to the synthesis of new transition metal-based catalysts, such as metallocenes, to produce new products.

\subsection{2}

\section{Fundamental and Engineering Sciences}

Apart from the various polymerization mechanisms involved, a large number of other disciplines will have to be involved, according to the matrix depicted in Figure 1.10.

Thermodynamics is essential to understand the physicochemical properties of the individual reactants, solvents, and products involved (Chapter 2). Also, it provides information on the interaction between the various components present in the reaction mixture, from which phenomena such as phase behavior and partitioning can be derived. This information is usually accessible by using the appropriate equation of state for a given system studied. A close collaboration between chemical physicists, chemists, and chemical engineers is required to take full advantage of this fundamental knowledge.

Polymer solutions (solid, bulk, solution, complex media) have to be characterized by several specific analytical tools (Chapter 20). Techniques such as NMR, ESR, 
electron microscopy, chromatography, electrophoresis, viscometry, calorimetry, and laser diffraction are widely used to determine polymer properties, often in combination. The main characteristics being analyzed are the chain length distribution, degree of branching, composition, tacticity, morphology, particle size, and chemical and mechanical properties. Polymer mechanics (Chapter 14) usually concerns the final product rather than the polymerization reaction. Nevertheless, as polymers are usually judged on their end-use properties (Chapter 13), the final product needs specific and often customer-based analysis. This is described more specifically for two application areas, namely the use of thermosets for coating applications (Chapter 16) and the production of polymeric fibers (Chapter 17).

Measurement and control are indispensable to achievement of a robust and safe process (Chapter 12). Since the early 1990s, a tremendous effort has been observed in the development of new in-line analytical techniques, including spectroscopy (UV, IR, Raman, laser, and so on), ultrasonic sensing, chromatography, and diffraction or electrical methods. New control schemes appear where the reaction is performed just below the constraint limits, independently of the reaction kinetics. All these techniques tend to lead to safer and more robust processes while increasing productivity and product quality at the same time.

Safety cannot be treated as a separate discipline as it is already integrated from the early chemistry and process development (Chapter 11). Safety deals with a wide variety of technological aspects with respect to the environment (water, air, soil, and living species). However, economic aspects are usually taken into consideration also. Modern process development intrinsically includes safety and environmental aspects in all stages of the development.

Modeling is probably the tool of excellence for engineers (Chapter 9). It is used to simulate the reaction and the process system in order to shorten the time for development. It is based on models that can be physical or chemical, semiempirical or empirical, descriptive or more fundamental. To describe the development of the molecular weight distribution upon reaction, moment methods or equations based on population balance are often used.

Scaleup is a widely used term to define the methodology that allows scaling up of a process from small to larger scale (Chapter 10). Often the scaleup process begins with a scaledown approach in order to have reliable and representative equipment already at the laboratory scale. Scaleup is always dependent on the system studied and requires a proper understanding of the performance of process equipment involved at different scales. In polymer reaction engineering, heat transfer and mixing can be considered as two major issues in this perspective. Modern computing techniques such as computational fluid dynamics and process simulation become more and more important in the optimization of process parameters and the equipment hardware.

Volatile organic compound (VOC) content in the final product is related to product properties and legislation (FDA approval in the USA, for example). All the processes aiming to lower the residual VOC content in the product are denoted as "removable" (Chapter 18). These processes can differ from each other, depending on 
the techniques involved. Devolatilization, post-process reaction, and extraction are some of the methodologies employed for this purpose.

Stability and degradation of polymers (Chapter 15) become relevant especially during post processing or moulding processes. Temperature, oxidation and mechanic stresses are the main contributors to product degradation.

Currently, there is a strong emphasis on the synthesis of novel functional polymers shaped on a nano scale (Chapter 19) and the development of sustainable production processes (Chapter 21). The latter includes process intensification as a methodology, the use of "green" solvents, and the use of renewable resources. Many of the new processes under development are focusing on one or more of these topics, for which the use of supercritical fluids is currently being implemented on an industrial scale.

\section{6}

\section{The Future: Product-inspired Polymer Reaction Engineering}

Innovation times in industry have shown a steady decrease since the 1970s. Classic thinking is that process development becomes increasingly important as industry matures [23]. This is due to the fact that in an early phase of the lifetime of an industry, when product concepts are still being created, the rate of product innovation exceeds the rate of process innovation. This period continues until a dominant design has emerged and opportunities for radical product innovation decrease. In this phase, the shift is toward process innovations to reduce cost price.

The half-time of product innovation (time-to-market) in the early 1970s was about ten years. Currently, two years is often considered long. This acceleration of innovation time is the result of competitive pressure in the market. As a rule of thumb, the first company to enter the market with a new product can get up to $60 \%$ of market share, so there is a high reward for being first.

As has been discussed above, chemical engineering has been the basis for polymer reaction engineering in the past. In recent discussions, however, it has been emphasized that a need exists to refocus chemical engineering toward productdriven process engineering $[24,25]$. The thinking about a process should then start with the customer or consumer: which of the two depends on the structure of the supply chain. The wishes of the consumer and consumer-perceived product properties have to be translated into physical and chemical product properties. In this way, the main physical attributes of a product are determined, including an idea about the microstructure. Next, a functional analysis is performed to determine the lowest number of transformations needed to create the product; this is followed by a morphological analysis [26]. Finally, a conceptual process design exercise is performed to generate possible process routes to achieve the desired product properties. This sequence of events is the core of product-inspired polymer reaction engineering. A key characteristic of this approach is the fact that it avoids the classical "unit operation trap", because it does not fix the mindset to consider only traditional reactor design and separation process steps to build a process. 
1.7

\section{Concluding Remarks}

In the foregoing we have presented a general framework for sustainable polymer reaction engineering. Its most important characteristic lies in the concerted multidisciplinary approach, rather than focusing on individual competencies. Given the volume of polymer production, it will be of major importance that environmental and safety issues become an integral part of the development process. In combination with tools such as life cycle analysis and product-inspired PRE, this will allow the development of sustainable new polymer processes.

\section{References}

1 Association of Plastics Manufacturers in Europe, Annual report, 2002.

2 H. Staudinger, Chem. Ber., 1920, 53, 1073.

3 W. Kunn, Berichte de Deutschen Chem. Gesellsch., 1930, 63, 1503.

4 W. H. Chalmers, J. Am. Chem. Soc., 1934, 56, 912.

5 H. Dostal, H. Mark, Trans. Faraday Soc., 1936, 32, 54

6 G. V. Schulz, Z. Physik. Chem., 1935, B30, 379.

7 P. J. Flory, J. Am. Chem. Soc., 1936, 58, 1877.

8 W. H. Carothers, US Patent 2130 948, 1937.

9 E. W. Fawcett, R. O. Gibson, J. Chem. Soc., 1934, 386.

10 K. G. Denbigh, Trans. Faraday Soc., 1947, 43, 648.

11 K. Ziegler, E. Holzkamp, H. Breil, H. Martin, Angew. Chem., 1955, 67, 541.

12 P. W. Morgan, S. L. Kwolek, Macromolecules, 1975, 8, 104.

13 H. Sasabe, T. Wada, Polymers for electronic applications, in: Comprehensive Polymer Science, vol. 7, S. L. Aggarwal (Ed.), Pergamon Press, Oxford, 1989.

14 J. K. J. van Duren, J. Loos, F. Morrissey, C. M. Leewis, K. P. H.
Kivits, L. J. IJZEndoorn, M. T.

Rispens, J. C. Hummelen, R. A. J. Janssen, Adv. Funct. Mater., 2002, 12, 665.

15 W. Kaminsky, H. Sinn (Eds.) Transition metals and organometallics as catalysts for olefin polymerisation, Springer Verlag, Berlin, 1987.

16 J. M. Benedikt, B. L. Goodali, Metallocene-catalyzed polymers, B.F. Goodrich, Brecksville, 1998.

17 J. Sinke, Appl. Comp. Mater., 2003, 10, 293.

18 E. R. Howells, Chem. Ind., 1982, 508.

19 A. Penlidis, Can. J. Chem. Eng., 1994, $72,385$.

20 A. SAPre, J. R. Katzer, Ind. Eng. Chem. Res., 1995, 34, 2202.

21 A. Azapagic, Chem. Eng. J., 1999, 73, 1.

22 P. Eyerer, J. Polym. Eng., 1996, 15, 197.

23 W. J. Abernathy, J. M. Utterback, Technol. Rev., 1978, 80, 40.

24 E. L. Cussler, G. D. Moggeridge, Chemical product design, Cambridge University Press, Cambridge, 2001.

25 E. L. Cussler, J. Wei, AIChE J., 2003, 49, 1072.

26 C. J. King, AIChE Monograph Ser., 1974, 70, 1 
